\title{
An MAGDM Approach Combining Numerical Values with Uncertain Linguistic Information and Its Application in Evaluation of R\&D Projects
}

\author{
Xin-Bao LIU \\ School of Management, Hefei University of Technology \\ 230009 Hefei, Anhui, P. R. China \\ lxinbao@mail.hf.ah.cn \\ Feng PEI* \\ School of Management, Hefei University of Technology \\ 230009 Hefei, Anhui, P. R. China \\ pf98612@yahoo.com.cn \\ Jian-Bo YANG \\ Manchester Business School, The University of Manchester, \\ Manchester, M15 6PB, UK \\ jian-bo.yang@manchester.ac.uk \\ Shan-Lin YANG \\ School of Management, Hefei University of Technology, \\ 230009 Hefei, Anhui, P. R. China \\ slyang@mail.hf.ah.cn \\ Received: $12-08-2009$ \\ Accepted: 09-09-2010
}

\begin{abstract}
In multi-attribute group decision making (MAGDM) problems, decision attributes of alternatives are often considered as with quantitative and qualitative information. Therefore decision making problems may include preference information in different formats. In this paper, a multi-attribute group decision making model based on numerical and uncertain linguistic information is investigated. Uncertain linguistic information reflects the subjectivity and uncertainty of evaluation with respect to qualitative attributes. A transformation function and an extended TOPSIS procedure are proposed to deal with this MAGDM model with numerical and uncertain linguistic information. In order to implement the TOPSIS procedure, the distance of interval numbers and the distance of n-dimensional interval numbers are defined, they are both in form of interval numbers to preserve the uncertainty of original information. The proposed approach is illustrated by a numerical example, and is applied in the evaluation of $R \& D$ projects in the final part of the paper.
\end{abstract}

Keywords: MAGDM; TOPSIS; Uncertain linguistic variables; Transformation function

\section{Introduction}

Multi-attribute group decision making (MAGDM) is to select a solution by multiple experts' assessments from a given set of alternatives that are characterized by multiple attributes or to rank the alternatives. It can be expressed in matrix format as follows:

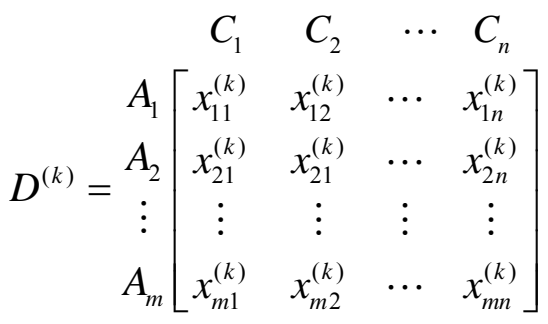

$$
\begin{aligned}
& \Lambda=\left(\lambda_{1}, \lambda_{2}, \cdots, \lambda_{1}\right)
\end{aligned}
$$




$$
W^{(k)}=\left(w_{1}^{(k)}, w_{2}^{(k)}, \cdots, w_{n}^{(k)}\right)
$$

where $A_{1}, A_{2}, \cdots, A_{m}$ are possible alternatives among which decision makers have to choose, $C_{1}, C_{2}, \cdots, C_{n}$ are attributes on which alternative performances are measured, $D^{(k)}$ is the decision matrix given by the $k^{\text {th }}$ expert, with its elements $X_{i j}^{(k)}$ being the performance ratings of alternative $A_{i}$ with respect to attribute $C_{j}$, $\lambda_{k}$ is the weight of the $k^{\text {th }}$ expert, $W^{(k)}$ is the weighting vector of attributes given by the $k^{\text {th }}$ expert.

In real decision making environments, it is common to find problems with both quantitative and qualitative attributes. Usually quantitative attributes are assessed by means of numerical values, while qualitative attributes are difficult to assess with numerical values. In the latter case, the use of linguistic approach has provided good results. ${ }^{1,2}$ Therefore, the decision making problems may include many different types of preference information such as number, interval and linguistic values. In order to deal with these preference information in different formats, some researches have been done. ${ }^{3-5}$ In many decision making problems, however, decision makers (DMs) may not be able to provide exact assessments of alternatives because of the complexity of assessment and the limited knowledge of DMs in dealing with new decision making problems. So decision information given by $\mathrm{DMs}$ may be uncertain. Zeshui $\mathrm{Xu}$ presented the concept of uncertain linguistic variables, ${ }^{6}$ which can be considered as intervals of linguistic terms. Uncertain linguistic variables base on a continuous term set and they allow the uncertainty of DMs' evaluation. In this paper, we present a multi-attribute group decision making (MAGDM) model with both uncertain linguistic information and numerical information.

Decision making problems with linguistic information have received wide attention over the past decade. ${ }^{7-11}$ There are several methods which have been proposed for dealing with linguistic information ${ }^{12}$ : (1) The extension principle based method for operations on fuzzy numbers that support the semantics of the linguistic labels. (2) The symbolic method for computations on the indexes of the linguistic terms. (3) A fuzzy linguistic model based method for the linguistic information with a pair of values called 2tuple, composed by a linguistic term and a number. (4)
The direct computing with words method. In this paper, we use the way similar to (2) to deal with the uncertain linguistic information. A transformation function is defined to transform uncertain linguistic information into interval numbers, and then the technique for order preference by similarly to ideal solution (TOPSIS) is extended to deal with this MAGDM model with interval numbers.

The TOPSIS approach was first developed by Hwang and Yoon ${ }^{13}$ for solving a quantitative MADM problem. It is based on the principle that the chosen alternative should have the shortest distance to the positive ideal solution (PIS) and the farthest distance to the negative ideal solution (NIS). The PIS is a hypothetical best alternative, which takes the best value on each attribute, while the NIS is a hypothetical worst alternative, which takes the worst value on each attribute. The TOPSIS approach is widely discussed in literatures. ${ }^{14-18}$ Since the complexity of decision making problems in practice, TOPSIS has been extended to deal with MADM problems under many kinds of environments such as fuzzy environments, ${ }^{19-23}$ group decision-making environments, ${ }^{24-27}$ etc. The aim of this paper is the development of a TOPSIS procedure for dealing with MAGDM problems based on interval numbers. In order to preserve the uncertainty of original information, the defined PIS, NIS and distance index are not crisp values but interval numbers.

The rest of the paper is organized as follows: Section 2 briefly introduces many basic definitions and their properties. Section 3 introduces the extended TOPSIS procedure of MAGDM with interval numbers. In section 4, an example is shown to illustrate the proposed approach. Section 5 is a case study about the evaluation of strategic research \& development (R\&D) projects. The paper is concluded in Section 6.

\section{Preliminaries}

The linguistic approach is a qualitative evaluation of alternatives by means of linguistic variables. Suppose that

$$
S=\left\{s_{i} \mid i=0,1, \cdots, T\right\}
$$

is a finite and completely ordered discrete term set, where $S_{i}$ represents a possible value for a linguistic variable. For example, a set of nine terms could be 
$S=\left\{S_{0}=\right.$ extremely poor; $S_{1}=$ very poor; $S_{2}=$ poor;

$S_{3}=$ slightly poor; $S_{4}=$ fair; $S_{5}=$ slightly good;

$S_{6}=$ good; $S_{7}=$ very good; $S_{8}=$ extremely good $\}$.

The term set $S$ satisfies the following conditions:

(i) $S$ is ordered: $S_{i} \geqslant s_{j}$ if and only if $i \geq j$;

(ii) There is the negation operator: neg $\left(S_{i}\right)=S_{j}$ such that $j=T-i$;

To preserve all the given information, we extend the discrete term set $S$ to a continuous term set

$$
\bar{S}=\left\{s_{\alpha} \mid s_{0} \leqslant s_{\alpha} \leqslant s_{T}, \alpha \in[0, T]\right\}
$$

whose elements also meet all the characteristics above.

Definition 1. ${ }^{6} \tilde{S}=\left[s_{\alpha}, s_{\beta}\right]$ is called the uncertain

linguistic variable, where $s_{\alpha}, s_{\beta} \in \bar{S}, s_{\alpha}$ and $s_{\beta}$ are the lower and upper limits respectively.

Uncertain linguistic variable is an interval of linguistic evaluation. It allows the uncertainty of expert's assessments. For example, $\left[S_{5}, S_{6}\right]$ means the alternative is evaluated between "slightly good" and "good". According to the characteristic of uncertain linguistic variable, we construct a transformation function to convert uncertain linguistic variables to interval numbers.

Definition 2. Let $\widetilde{S}$ be a set of uncertain linguistic variables and $T$ a set of interval numbers. The mapping $\varphi: \widetilde{S} \rightarrow T$ is defined as

$$
\varphi(\tilde{s})=[\alpha, \beta], \quad \forall \tilde{s}=\left[s_{\alpha}, s_{\beta}\right] \in \tilde{S} .
$$

In decision making problems with interval information, the ranking of interval numbers is an important part. The comparison method of interval numbers given by Nakahara et al. ${ }^{28}$ recurs to the following conception:

Definition 3. Let $t_{1}=\left[\alpha_{1}, \beta_{1}\right]$ and $t_{2}=\left[\alpha_{2}, \beta_{2}\right]$ be interval numbers, $l_{1}=\beta_{1}-\alpha_{1}, l_{2}=\beta_{2}-\alpha_{2}$. Then the degree of possibility of $t_{1} \geq t_{2}$ is defined as

$$
p\left(t_{1} \geq t_{2}\right)=\min \left\{\max \left(\frac{\beta_{1}-\alpha_{2}}{l_{1}+l_{2}}, 0\right), 1\right\}
$$

Similarly, the degree of possibility of $t_{2} \geq t_{1}$ is defined as

$$
p\left(t_{2} \geq t_{1}\right)=\min \left\{\max \left(\frac{\beta_{2}-\alpha_{1}}{l_{1}+l_{2}}, 0\right), 1\right\}
$$

Theorem 1. The degree of possibility defined in definition 3 satisfies the following properties:

(i) $0 \leq p\left(t_{1} \geq t_{2}\right) \leq 1, \quad 0 \leq p\left(t_{2} \geq t_{1}\right) \leq 1$;

(ii) $p\left(t_{1} \geq t_{2}\right)+p\left(t_{2} \geq t_{1}\right)=1$, especially, $p\left(t_{1} \geq t_{1}\right)=$ $p\left(t_{2} \geq t_{2}\right)=1 / 2$;

(iii) $p\left(t_{1} \geq t_{2}\right) \geq \frac{1}{2}$ if and only if $\alpha_{1}+\beta_{1} \geq$ $\alpha_{2}+\beta_{2}$. Especially, $p\left(t_{1} \geq t_{2}\right)=\frac{1}{2}$ if and only if $\alpha_{1}+\beta_{1}=\alpha_{2}+\beta_{2}$.

According to the principle of TOPSIS (i.e. the chosen alternative should have the shortest distance to the positive ideal solution and the farthest distance from the negative ideal solution), the distance measurement of alternatives is a key step which should affect the final ranking of alternatives. The existing distance measurements of interval numbers are crisp numbers ${ }^{19}$, which eliminate the uncertainty of original assessments. In order to reduce the lost of information, we try to present a new distance measurement which is in the form of interval numbers.

Definition 4. Let $t_{1}=\left[\alpha_{1}, \beta_{1}\right]$ and $t_{2}=\left[\alpha_{2}, \beta_{2}\right]$ be interval numbers. The distance of $t_{1}$ and $t_{2}$ is defined as

$$
\begin{array}{r}
d\left(t_{1}, t_{2}\right)=\left[\min \left(\left|\alpha_{1}-\alpha_{2}\right|,\left|\beta_{1}-\beta_{2}\right|\right),\right. \\
\left.\max \left(\left|\alpha_{1}-\alpha_{2}\right|,\left|\beta_{1}-\beta_{2}\right|\right)\right] .
\end{array}
$$

It is easy to see that $d\left(t_{1}, t_{2}\right)$ is identical with the distance of crisp numbers when $\alpha_{1}=\beta_{1}$ and $\alpha_{2}=\beta_{2}$. Especially, when the span of the two intervals $t_{1}$ and $t_{2}$ are the same, the distance $d\left(t_{1}, t_{2}\right)$ is degenerated to a crisp number which equals to the distance of the midpoints of $t_{1}$ and $t_{2}$. 
Theorem 2. The distance of interval numbers defined in definition 4 satisfies the following properties:

(i) $d\left(t_{1}, t_{2}\right) \geq[0,0]$, and $d\left(t_{1}, t_{2}\right)=[0,0]$ if and only if $t_{1}=t_{2}$,

(ii) $d\left(t_{1}, t_{2}\right)=d\left(t_{2}, t_{1}\right)$,

(iii) $p\left\{d\left(t_{1}, t_{2}\right) \leq d\left(t_{1}, t_{3}\right)+d\left(t_{2}, t_{3}\right)\right\} \geq \frac{1}{2}$

where $t_{1}, t_{2}, t_{3}$ are arbitrary interval numbers.

Proof. Properties (i) and (ii) are evident and their proofs are omitted here. The proof of property (iii) is as follows:

$$
\begin{aligned}
& \text { According to definition } 4, \text { we have } \\
& d\left(t_{1}, t_{2}\right)=\left[\min \left(\left|\alpha_{1}-\alpha_{2}\right|,\left|\beta_{1}-\beta_{2}\right|\right),\right. \\
& \left.\max \left(\left|\alpha_{1}-\alpha_{2}\right|,\left|\beta_{1}-\beta_{2}\right|\right)\right] \triangleq[a, b], \\
& \begin{array}{r}
d\left(t_{1}, t_{3}\right)=\left[\min \left(\left|\alpha_{1}-\alpha_{3}\right|,\left|\beta_{1}-\beta_{3}\right|\right),\right. \\
\left.\max \left(\left|\alpha_{1}-\alpha_{3}\right|,\left|\beta_{1}-\beta_{3}\right|\right)\right] \triangleq[c, d], \\
d\left(t_{2}, t_{3}\right)=\left[\min \left(\left|\alpha_{2}-\alpha_{3}\right|,\left|\beta_{2}-\beta_{3}\right|\right),\right. \\
\left.\max \left(\left|\alpha_{2}-\alpha_{3}\right|,\left|\beta_{2}-\beta_{3}\right|\right)\right] \triangleq[e, f] .
\end{array}
\end{aligned}
$$

So

$$
\begin{aligned}
d\left(t_{1}, t_{3}\right)+d\left(t_{2}, t_{3}\right)= & {[c, d]+[e, f] } \\
& =[c+e, d+f] .
\end{aligned}
$$

Since

$$
\begin{aligned}
(c+e) & +(d+f)=(c+d)+(e+f) \\
= & \left|\alpha_{1}-\alpha_{3}\right|+\left|\beta_{1}-\beta_{3}\right|+\left|\alpha_{2}-\alpha_{3}\right|+\left|\beta_{2}-\beta_{3}\right| \\
= & \left|\alpha_{1}-\alpha_{3}\right|+\left|\alpha_{2}-\alpha_{3}\right|+\left|\beta_{1}-\beta_{3}\right|+\left|\beta_{2}-\beta_{3}\right| \\
\geq & \left|\alpha_{1}-\alpha_{2}\right|+\left|\beta_{1}-\beta_{2}\right|=a+b,
\end{aligned}
$$

then according to the $3^{\text {rd }}$ conclusion of theorem 1 , we have

$$
p\left\{d\left(t_{1}, t_{2}\right) \leq d\left(t_{1}, t_{3}\right)+d\left(t_{2}, t_{3}\right)\right\} \geq \frac{1}{2} .
$$

In the multi-attribute decision making environment, alternatives are evaluated under multiple attributes. So the evaluation information of each alternative can be considered as a vector whose dimension is the number of attributes. Well then the distance of alternatives can be described as the distance of $n$-dimensional vectors.

Definition 5. Let $M=\left(\left[\alpha_{1}, \beta_{1}\right],\left[\alpha_{2}, \beta_{2}\right], \cdots,\left[\alpha_{n}, \beta_{n}\right]\right)$ and $\quad N=\left(\left[\gamma_{1}, \delta_{1}\right],\left[\gamma_{2}, \delta_{2}\right], \cdots,\left[\gamma_{n}, \delta_{n}\right]\right)$ be $n-$ dimensional interval numbers, the distance of $M$ and $N$ is defined as

$$
\begin{aligned}
d(M, N)= & {\left[\min \left(\sqrt[k]{\sum_{j=1}^{n}\left|\alpha_{j}-\gamma_{j}\right|^{k}}, \sqrt[k]{\sum_{j=1}^{n}\left|\beta_{j}-\delta_{j}\right|^{k}}\right),\right.} \\
& \left.\max \left(\sqrt[k]{\sum_{j=1}^{n}\left|\alpha_{j}-\gamma_{j}\right|^{k}}, \sqrt[k]{\sum_{j=1}^{n}\left|\beta_{j}-\delta_{j}\right|^{k}}\right)\right]
\end{aligned}
$$

where $k$ is an arbitrary natural number.

It is easy to see that the distance defined in definition 5 is consistent with definition 4 for $n=1$. When $k=1$, the distance measurement is the absolute value distance. When $k=2$, the distance measurement is the Euclidean distance. When $k=+\infty$, the distance measurement is the Chebyshev distance. When $k$ is increasing from 1 to $+\infty$, the attribute which has the biggest difference become more important, and it become the only acting attribute when $k=+\infty$. The intuitionistic explanation of the distance of 2dimensional interval numbers (for $k=2$ ) is shown as follows.

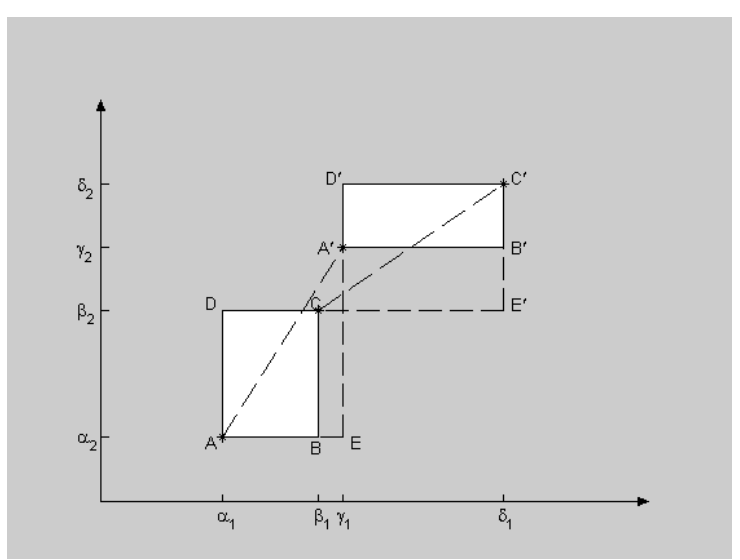

Fig. 1. The distance of 2-dimensional interval numbers

Suppose $M=\left\{\left[\alpha_{1}, \beta\right],\left[\alpha_{2}, \beta\right]\right\}$ and $N=\left\{\left[\gamma_{1}, \delta_{1}\right],\left[\gamma_{2}, \delta_{2}\right]\right\}$ are 2-dimensional interval numbers which correspond to the two rectangles shown in Fig. 1. The $x$-axis and $y$ axis denote the first and second components of the 2dimensional interval numbers respectively. According to definition 5, the distance between $M$ and $N$ is

$$
\begin{aligned}
d(M, N)= & {\left[\min \left(\sqrt{\left(\alpha_{1}-\gamma_{1}\right)^{2}+\left(\alpha_{2}-\gamma_{2}\right)^{2}}, \sqrt{\left(\beta_{1}-\delta_{1}\right)^{2}+\left(\beta_{2}-\delta_{2}\right)^{2}}\right),\right.} \\
& \left.\max \left(\sqrt{\left(\alpha_{1}-\gamma_{1}\right)^{2}+\left(\alpha_{2}-\gamma_{2}\right)^{2}}, \sqrt{\left(\beta_{1}-\delta_{1}\right)^{2}+\left(\beta_{2}-\delta_{2}\right)^{2}}\right)\right] .
\end{aligned}
$$


From Fig. 1, we can see that $\left|\alpha_{1}-\gamma_{1}\right|$ is the distance $d_{A E}$ between vertex $A$ and $E$, while $\left|\alpha_{2}-\gamma_{2}\right|$ is the distance $d_{A^{\prime} E}$ between vertexes $A^{\prime}$ and $E$. So we have

$$
\sqrt{\left(\alpha_{1}-\gamma_{1}\right)^{2}+\left(\alpha_{2}-\gamma_{2}\right)^{2}}=\sqrt{d_{A E}^{2}+d_{A^{\prime} E}^{2}}=d_{A A^{\prime}} .
$$

Similarly, we have

$$
\sqrt{\left(\beta_{1}-\delta_{1}\right)^{2}+\left(\beta_{2}-\delta_{2}\right)^{2}}=\sqrt{d_{C E^{\prime}}^{2}+d_{C^{\prime} E^{\prime}}^{2}}=d_{C C^{\prime}} .
$$

So the distance between $M$ and $N$ is

$$
\begin{aligned}
d(M, N)= & {\left[\min \left(\sqrt{\left(\alpha_{1}-\gamma_{1}\right)^{2}+\left(\alpha_{2}-\gamma_{2}\right)^{2}}, \sqrt{\left(\beta_{1}-\delta_{1}\right)^{2}+\left(\beta_{2}-\delta_{2}\right)^{2}}\right),\right.} \\
& \left.\max \left(\sqrt{\left(\alpha_{1}-\gamma_{1}\right)^{2}+\left(\alpha_{2}-\gamma_{2}\right)^{2}}, \sqrt{\left(\beta_{1}-\delta_{1}\right)^{2}+\left(\beta_{2}-\delta_{2}\right)^{2}}\right)\right] \\
= & {\left[\min \left(d_{A A^{\prime}}, d_{C C^{\prime}}\right), \max \left(d_{A A^{\prime}}, d_{C C^{\prime}}\right)\right] . }
\end{aligned}
$$

Especially when $\beta_{1}-\alpha_{1}=\delta_{1}-\gamma_{1}$ and

$\beta_{2}-\alpha_{2}=\delta_{2}-\gamma_{2}$, we have

$$
\begin{aligned}
d(M, N) & =\sqrt{\left(\alpha_{1}-\gamma_{1}\right)^{2}+\left(\alpha_{2}-\gamma_{2}\right)^{2}} \\
& =\sqrt{\left(\beta_{1}-\delta_{1}\right)^{2}+\left(\beta_{2}-\delta_{2}\right)^{2}} .
\end{aligned}
$$

It means that when the shapes of the two rectangles are same (not allowing the rotation), then one of them can superpose the other by moving, and the distance of the two rectangles equals to the distance of their centres.

Theorem 3. The distance of $n$-dimension interval numbers defined in definition 5 satisfies the following properties:

(i) $d(M, N) \geq[0,0], d(M, N)=[0,0]$ if and only if $M=N$;

(ii) $d(M, N)=d(N, M)$;

(iii) $p\{d(M, N) \leq d(M, L)+d(N, L)\} \geq \frac{1}{2}$.

where $M, N$ and $L$ are arbitrary $n$-dimension interval numbers.

The proof of Theorem 3 is similar to the proof of Theorem 2.

\section{The proposed approach}

In this section, we present the model of MAGDM problem with numerical and uncertain linguistic information. The extended TOPSIS procedure is presented to deal with the model.

The MAGDM problem with numerical and uncertain linguistic information can be expressed in matrix format as

$$
\begin{aligned}
& \begin{array}{cccc}
C_{1} & C_{2} & \cdots & C_{n}
\end{array} \\
& D^{(k)}=A_{2}\left[\begin{array}{cccc}
A_{1} \\
\vdots \\
A_{m}(k) & \tilde{S}_{12}^{(k)} & \ldots & \tilde{S}_{1 n}^{(k)} \\
\tilde{S}_{21}^{(k)} & \tilde{S}_{22}^{(k)} & \ldots & \tilde{S}_{2 n}^{(k)} \\
\vdots & \vdots & \vdots & \vdots \\
\tilde{S}_{m 1}^{(k)} & \tilde{S}_{m 2}^{(k)} & \ldots & \tilde{S}_{m n}^{(k)}
\end{array}\right] \\
& \Lambda=\left(\lambda_{1}, \lambda_{2}, \cdots, \lambda_{l}\right) \\
& W^{(k)}=\left(w_{1}^{(k)}, w_{2}^{(k)}, \cdots, w_{n}^{(k)}\right)
\end{aligned}
$$

where $A_{1}, A_{2}, \cdots, A_{m}$ are possible alternatives among which decision makers have to choose, $C_{1}, C_{2}, \cdots, C_{n}$ are attributes with which alternative performances are measured, $D^{(k)}$ is the decision matrix given by the $k^{\text {th }}$ expert with its elements $\tilde{s}_{i j}^{(k)}$ being the performance ratings of alternative $A_{i}$ with respect to the attribute $C_{j}$, $\lambda_{k}$ is the weight of the $k^{\text {th }}$ expert, and $W^{(k)}$ is the weighting vector of attributes given by the $k^{\text {th }}$ expert. The performance ratings on qualitative attributes are uncertain linguistic variables, while for quantitative attributes, the performance ratings are crisp values or interval numbers.

The extended TOPSIS procedure for the above model is given as follows:

Step 1. Convert all the uncertain linguistic variables in decision matrices to interval numbers by using the mapping $\varphi$ to get decision matrices $T^{(k)}=\left(t_{i j}^{(k)}\right), k=1,2, \cdots, l$. So the elements of $T^{(k)}$ are crisp numbers or interval numbers.

Step 2. Aggregate the weights of attributes given by $l$ DMs to get the aggregated weight $W=\left(w_{1}, w_{2}, \cdots, w_{n}\right)$ as

$$
w_{j}=\sum_{k=1}^{l} \lambda_{k} w_{j}^{(k)},(j=1,2, \cdots, n)
$$

Step 3. Aggregate the decision matrices of $l \mathrm{DMs}$ as

$$
t_{i j}=\sum_{k=1}^{l} \lambda_{k} t_{i j}^{(k)}
$$

for all $i=1,2, \cdots, m ; j=1,2, \cdots, n$. The addition and scalar multiplication are the corresponding operations of interval numbers. 
Step 4. In order to transform various scales of attributes into a comparable scale, we need to normalize the data of decision matrix.

$$
\begin{array}{r}
y_{i j}^{L}=t_{i j}^{L} / \sqrt{\sum_{i=1}^{m} \frac{1}{2}\left[\left(t_{i j}^{L}\right)^{2}+\left(t_{i j}^{U}\right)^{2}\right]} \\
y_{i j}^{U}=t_{i j}^{U} / \sqrt{\sum_{i=1}^{m} \frac{1}{2}\left[\left(t_{i j}^{L}\right)^{2}+\left(t_{i j}^{U}\right)^{2}\right]} \\
(i=1, \cdots, m ; j=1, \cdots, n)
\end{array}
$$

where

$$
y_{i j}=\left[y_{i j}^{L}, y_{i j}^{U}\right], t_{i j}=\left[t_{i j}^{L}, t_{i j}^{U}\right],(i=1, \cdots, m ; j=1, \cdots, n) \text {. }
$$

Crisp numbers can also be normalized by Eq. (5) and Eq. (6), since they can be seemed as special interval numbers whose lower and upper limits are equal.

Step 5. Considering the different importance of each attribute, we construct the weighted normalized decision matrix as

$$
\begin{aligned}
& z_{i j}=w_{j} y_{i j}=\left[w_{j} y_{i j}^{L}, w_{j} y_{i j}^{U}\right] \\
& (i=1, \cdots, m ; j=1, \cdots, n)
\end{aligned}
$$

Step 6. Determine the positive ideal solution and the negative ideal solution as

$$
\begin{aligned}
A^{+} & =\left\{z_{1}^{+}, z_{2}^{+}, \cdots, z_{n}^{+}\right\} \\
& =\left\{\left(\max _{i} z_{i j} \mid j \in I\right),\left(\min _{i} z_{i j} \mid j \in J\right)\right\} \\
A^{-} & =\left\{z_{1}^{-}, z_{2}^{-}, \cdots, z_{n}^{-}\right\} \\
& =\left\{\left(\min _{i} z_{i j} \mid j \in I\right),\left(\max _{i} z_{i j} \mid j \in J\right)\right\}
\end{aligned}
$$

where $I$ is the set of subscripts associated with benefit attributes, and $J$ is the set of subscripts associated with cost attributes.

The maximum and minimum elements can be obtained by using definition 3. Let's take for example the calculation of $z_{1}^{+}$. Firstly, comparing the elements of vector $\left(z_{11}, z_{21}, \cdots, z_{m 1}\right)^{T}$ in pairs by using Eq. (1) to get $p_{i j}$, it represents the degree of possibility of $z_{i 1} \geq z_{j 1},(i, j=1,2, \cdots, m)$. Then constructing a complementary matrix $P=\left(p_{i j}\right)_{m \times m}$, where $p_{i j} \geq 0$, $p_{i i}=\frac{1}{2}$ and $p_{i j}+p_{j i}=1 \quad, \quad i, j=1,2, \cdots, m$. Secondly, adding the elements in each line of $P$, we get $p_{i}=\sum_{j=1}^{m} p_{i j}, i=1,2, \cdots, m$. Finally, rank all the arguments $Z_{i 1}(i=1,2, \cdots, m)$ in descending order in accordance with the order of $p_{i}(i=1,2, \cdots, m) . z_{1}^{+}$ is the maximum or minimum of $z_{i 1}(i=1,2, \cdots, m)$ depending upon whether $C_{1}$ is a benefit attribute or a cost one.

Step 7. Calculate the separations of alternatives $A_{i}=\left\{z_{i 1}, z_{i 2}, \cdots, z_{i n}\right\}, i=1,2, \cdots m$ from the positive ideal solution

$$
\begin{aligned}
A^{+}= & \left\{z_{1}^{+}, z_{2}^{+}, \cdots, z_{n}^{+}\right\} \\
& =\left\{\left[z_{1}^{+L}, z_{1}^{+U}\right],\left[z_{2}^{+L}, z_{2}^{+U}\right], \cdots,\left[z_{n}^{+L}, z_{n}^{+U}\right]\right\}
\end{aligned}
$$

and the negative ideal solution

$$
\begin{aligned}
A^{-}= & \left\{z_{1}^{-}, z_{2}^{-}, \cdots, z_{n}^{-}\right\} \\
& =\left\{\left[z_{1}^{-L}, z_{1}^{-U}\right],\left[z_{2}^{-L}, z_{2}^{-U}\right], \cdots,\left[z_{n}^{-L}, z_{n}^{-U}\right]\right\}
\end{aligned}
$$

respectively. It recurs to the concept of "the distance of n-dimensional interval numbers" (definition 5). In this paper, we use the traditional Euclidean distance to measure the separations, and the formulas are:

$$
\begin{array}{r}
d_{i}^{+}=d\left(A_{i}, A^{+}\right) \\
=\left[\operatorname { m i n } \left(\sqrt{\sum_{j=1}^{n}\left(z_{j}^{+L}-z_{i j}^{L}\right)^{2}}, \sqrt{\left.\sum_{j=1}^{n}\left(z_{j}^{+U}-z_{i j}^{U}\right)^{2}\right)},\right.\right. \\
\quad \max \left(\sqrt{\sum_{j=1}^{n}\left(z_{j}^{+L}-z_{i j}^{L}\right)^{2}}, \sqrt{\sum_{j=1}^{n}\left(z_{j}^{+U}-z_{i j}^{U}\right)^{2}}\right], \\
d_{i}^{-}=d\left(A_{i}, A^{-}\right) \\
=\left[\operatorname { m i n } \left(\sqrt{\sum_{j=1}^{n}\left(z_{j}^{-L}-z_{i j}^{L}\right)^{2}}, \sqrt{\left.\sum_{j=1}^{n}\left(z_{j}^{-U}-z_{i j}^{U}\right)^{2}\right)},\right.\right. \\
\quad \max \left(\sqrt{\sum_{j=1}^{n}\left(z_{j}^{-L}-z_{i j}^{L}\right)^{2}}, \sqrt{\sum_{j=1}^{n}\left(z_{j}^{-U}-z_{i j}^{U}\right)^{2}}\right] . \\
(i=1,2, \cdots, m)
\end{array}
$$

Step 8. The relative closeness coefficient of alternative $A_{i}$ with respect to $A^{+}$is defined as

$$
d_{i}=d_{i}^{-} /\left(d_{i}^{+}+d_{i}^{-}\right), \quad i=1,2, \cdots, m
$$

The addition and division in Eq. (10) are just the corresponding operations of interval numbers. Obviously, an alternative $A_{i}$ is closer to $A^{+}$and farther from $A^{-}$as $d_{i}$ approaches to 1 . Therefore, 
according to the closeness coefficient, we can determine the ranking order of all alternatives and select the best one from among a set of feasible alternatives.

\section{Numerical example}

In this section, a problem of supply chain partner selection is used to illustrate the proposed approach. A core enterprise is to choose a partner from five hardware manufacturers. The evaluation attributes are: the credit of the manufacturer $\left(C_{1}\right)$, the quality of its products $\left(C_{2}\right)$, the cost of manufacturing $\left(C_{3}\right)$, the period of manufacturing $\left(C_{4}\right)$, the ability of innovation $\left(C_{5}\right)$, the level of services $\left(C_{6}\right)$ and the compatibility of the manufacturer $\left(C_{7}\right)$. Five candidates (alternatives) $A_{j}$ $(j=1,2,3,4,5)$ are to be evaluated by three experts $E_{k}$ $(k=1,2,3)$ as follows:

$$
D^{(1)}=\left[\begin{array}{lllllll}
{\left[s_{7}, s_{8}\right]} & {\left[s_{5}, s_{6}\right]} & {\left[s_{5}, s_{7}\right]} & {\left[s_{6}, s_{7}\right]} & {\left[s_{6}, s_{8}\right]} & {\left[s_{7}, s_{8}\right]} & {\left[s_{5}, s_{7}\right]} \\
{\left[s_{5}, s_{6}\right]} & {\left[s_{6}, s_{7}\right]} & {\left[s_{4}, s_{5}\right]} & {\left[s_{5}, s_{6}\right]} & {\left[s_{4}, s_{5}\right]} & {\left[s_{6}, s_{8}\right]} & {\left[s_{6}, s_{7}\right]} \\
{\left[s_{6}, s_{8}\right]} & {\left[s_{5}, s_{7}\right]} & {\left[s_{6}, s_{8}\right]} & {\left[s_{5}, s_{7}\right]} & {\left[s_{6}, s_{7}\right]} & {\left[s_{5}, s_{7}\right]} & {\left[s_{5}, s_{6}\right]} \\
{\left[s_{5}, s_{7}\right]} & {\left[s_{4}, s_{5}\right]} & {\left[s_{6}, s_{7}\right]} & {\left[s_{6}, s_{8}\right]} & {\left[s_{5}, s_{6}\right]} & {\left[s_{4}, s_{5}\right]} & {\left[s_{6}, s_{8}\right]} \\
{\left[s_{4}, s_{5}\right]} & {\left[s_{6}, s_{8}\right]} & {\left[s_{5}, s_{6}\right]} & {\left[s_{4}, s_{5}\right]} & {\left[s_{5}, s_{7}\right]} & {\left[s_{6}, s_{7}\right]} & {\left[s_{4}, s_{5}\right]}
\end{array}\right],
$$$$
D^{(2)}=\left[\begin{array}{lllllll}
{\left[s_{4}, s_{6}\right]} & {\left[s_{6}, s_{7}\right]} & {\left[s_{4}, s_{5}\right]} & {\left[s_{5}, s_{7}\right]} & {\left[s_{7}, s_{8}\right]} & {\left[s_{5}, s_{6}\right]} & {\left[s_{6}, s_{8}\right]} \\
{\left[s_{6}, s_{7}\right]} & {\left[s_{5}, s_{7}\right]} & {\left[s_{6}, s_{8}\right]} & {\left[s_{5}, s_{6}\right]} & {\left[s_{5}, s_{7}\right]} & {\left[s_{6}, s_{7}\right]} & {\left[s_{5}, s_{6}\right]} \\
{\left[s_{6}, s_{8}\right]} & {\left[s_{6}, s_{7}\right]} & {\left[s_{6}, s_{8}\right]} & {\left[s_{5}, s_{7}\right]} & {\left[s_{5}, s_{6}\right]} & {\left[s_{6}, s_{8}\right]} & {\left[s_{6}, s_{7}\right]} \\
{\left[s_{7}, s_{8}\right]} & {\left[s_{5}, s_{6}\right]} & {\left[s_{6}, s_{7}\right]} & {\left[s_{6}, s_{8}\right]} & {\left[s_{5}, s_{6}\right]} & {\left[s_{6}, s_{7}\right]} & {\left[s_{5}, s_{6}\right]} \\
{\left[s_{5}, s_{6}\right]} & {\left[s_{6}, s_{8}\right]} & {\left[s_{4}, s_{7}\right]} & {\left[s_{5}, s_{6}\right]} & {\left[s_{6}, s_{7}\right]} & {\left[s_{6}, s_{8}\right]} & {\left[s_{6}, s_{8}\right]}
\end{array}\right],
$$

$$
D^{3)}=\left[\begin{array}{lllllll}
{\left[s_{7}, s_{8}\right]} & {\left[s_{6}, s_{8}\right]} & {\left[s_{5}, s_{6}\right]} & {\left[s_{5}, s_{6}\right]} & {\left[s_{5}, s_{7}\right]} & {\left[s_{6}, s_{7}\right]} & {\left[s_{5}, s_{6}\right]} \\
{\left[s_{5}, s_{6}\right]} & {\left[s_{6}, s_{8}\right]} & {\left[s_{7}, s_{8}\right]} & {\left[s_{6}, s_{7}\right]} & {\left[s_{6}, s_{7}\right]} & {\left[s_{4}, s_{6}\right]} & {\left[s_{5}, s_{6}\right]} \\
{\left[s_{6}, s_{7}\right]} & {\left[s_{6}, s_{7}\right]} & {\left[s_{6}, s_{8}\right]} & {\left[s_{5}, s_{6}\right]} & {\left[s_{7}, s_{8}\right]} & {\left[s_{7}, s_{8}\right]} & {\left[s_{5}, s_{7}\right]} \\
{\left[s_{4}, s_{5}\right]} & {\left[s_{6}, s_{7}\right]} & {\left[s_{4}, s_{6}\right]} & {\left[s_{7}, s_{8}\right]} & {\left[s_{5}, s_{6}\right]} & {\left[s_{6}, s_{7}\right]} & {\left[s_{6}, s_{7}\right]} \\
{\left[s_{5}, s_{7}\right]} & {\left[s_{5}, s_{7}\right]} & {\left[s_{4}, s_{6}\right]} & {\left[s_{4}, s_{7}\right]} & {\left[s_{4}, s_{5}\right]} & {\left[s_{5}, s_{6}\right]} & {\left[s_{6}, s_{7}\right]}
\end{array}\right] .
$$

The meaning of the above linguistic variables is: $S_{0}=$ extremely poor, $S_{1}=$ very poor, $S_{2}=$ poor, $S_{3}=$ slightly poor, $S_{4}=$ fair, $S_{5}=$ slightly good, $S_{6}=$ good, $S_{7}=$ very good, $S_{8}=$ extremely good. For example, the first element $\left[S_{4}, S_{6}\right]$ of decision matrix $D^{(2)}$ means the credit of candidate $A_{1}$ is evaluated between "fair" and "good" by expert $E_{2}$.
The weight vector of the three experts is $\Lambda=(0.3,0.4,0.3)$, and the weight vectors of the seven attributes given by the three experts are

$$
\begin{gathered}
W^{(1)}=(0.15,0.2,0.15,0.1,0.1,0.15,0.15), \\
W^{(2)}=(0.2,0.15,0.1,0.1,0.15,0.1,0.2), \\
W^{(3)}=(0.2,0.2,0.15,0.1,0.05,0.2,0.1) .
\end{gathered}
$$

According to the proposed steps, we first convert the uncertain linguistic variables in decision matrices to interval numbers by using the mapping $\varphi$. For example, the decision matrix $D^{(1)}$ is converted to

$$
T^{(1)}=\left[\begin{array}{lllllll}
{[7,8]} & {[5,6]} & {[5,7]} & {[6,7]} & {[6,8]} & {[7,8]} & {[5,7]} \\
{[5,6]} & {[6,7]} & {[4,5]} & {[5,6]} & {[4,5]} & {[6,8]} & {[6,7]} \\
{[6,8]} & {[5,7]} & {[6,8]} & {[5,7]} & {[6,7]} & {[5,7]} & {[5,6]} \\
{[5,7]} & {[4,5]} & {[6,7]} & {[6,8]} & {[5,6]} & {[4,5]} & {[6,8]} \\
{[4,5]} & {[6,8]} & {[5,6]} & {[4,5]} & {[5,7]} & {[6,7]} & {[4,5]}
\end{array}\right] .
$$

Then we get the aggregated weight vector of attributes

$W=(0.185,0.18,0.13,0.1,0.105,0.145,0.155)$.

The aggregated decision matrix is

$$
\begin{aligned}
& T=\left[\begin{array}{lll}
{[5.8,7.2]} & {[5.7,7.0]} & {[4.6,5.9]} \\
{[5.4,6.4]} & {[5.6,7.3]} & {[5.7,7.1]} \\
{[6.0,7.7]} & {[5.7,7.0]} & {[6.0,8.0]} \\
{[5.5,6.8]} & {[5.0,6.0]} & {[5.4,6.7]} \\
{[4.7,6.0]} & {[5.7,7.7]} & {[4.3,6.4]}
\end{array}\right. \\
& {[5.3,6.7] \quad[6.1,7.7] \quad[5.9,6.9] \quad[5.4,7.1]} \\
& {[5.3,6.3] \quad[5.0,6.4] \quad[5.4,7.0] \quad[5.3,6.3]} \\
& {[5.0,6.7][5.9,6.9][6.0,7.7][5.4,6.7] \text {. }} \\
& {[6.3,8.0] \quad[5.0,6.0] \quad[5.4,6.4] \quad[5.6,6.9]} \\
& [4.4,6.0] \quad[5.1,6.4] \quad[5.7,7.1] \quad[5.4,6.8]]
\end{aligned}
$$

The relative closeness coefficients of the five alternatives are $d_{1}=[0.3936,0.7353], d_{2}=[0.34986$, $0.6660], d_{3}=[0.5021,1.0271], d_{4}=[0.3593,0.5831]$, $d_{5}=[0.1733,0.6225]$.

According to definition 3, we can rank the order of $d_{i}(i=1,2, \cdots, 5)$ as $d_{3}>d_{1}>d_{2}>d_{4}>d_{5}$. So the ranking order of $A_{i}(i=1,2, \cdots, 5)$ is $A_{3} \succ A_{1} \succ A_{2} \succ A_{4} \succ A_{5}$. It may not be the unique ranking since all the relative closeness coefficients are overlapping, which owe to the uncertainty of initial evaluation. We further consider the following three accurate situations: the performance ratings of all alternatives are the lowest grade, the highest grade and 
the medial grade of the initial evaluation respectively. Using the traditional TOPSIS procedure, we obtain the ranking results are $A_{3} \succ A_{1} \succ A_{4} \succ A_{2} \succ A_{5}$, $A_{3} \succ A_{1} \succ A_{2} \succ A_{5} \succ A_{4}$, and $A_{3} \succ A_{1} \succ A_{2} \succ A_{4} \succ A_{5}$ respectively. Comparing the ranking result under uncertain environment with three accurate cases, we find that the ranking of $A_{3}$ and $A_{1}$ are unaltered and they are the first two alternatives. While the ranking of $A_{2}, A_{4}$ and $A_{5}$ changes. $A_{2}$ and $A_{5}$ are considered as the third one and the last one respectively three times of the four results.

\section{Case study: checkout and evaluation system of strategic $R \& D$ projects}

The case was originated from an analysis of the performance of several strategic research \& development (R\&D) projects for a car manufacturer in China, and the data was taken from a research project titled "Evaluation of R\&D projects and study on incentive mechanism of R\&D personnel of Jianghuai Automotive Co., Ltd (JAC)". The research was conducted in close collaboration with the leaders in the marketing department, manufacturing department, and human resource department of the company. The company has established a preliminary system of checkout and evaluation. However, the evaluation of the projects in the system is purely based on subjective analysis, some basic attributes are only roughly described, and some important attributes have not been established yet. Thus, there is a need to improve the current checkout and evaluation system and provide a more complete set of attributes and a more scientific and reliable evaluation system. This section is devoted to the development of such a system.

\subsection{Attributes for "checkout and evaluation system of strategic $R \& D$ projects”}

Twelve group meetings were held to have discussions with the faculties of the car factory. These face-to-face discussions helped us to understand their present project management and evaluation system, as well as the problems and recommendations provided by the faculties in each department. From these meetings and discussions, a hierarchy of attributes on which to evaluate the strategic $R \& D$ projects is developed.
In the attribute hierarchy, three general attributes are considered: "Quality of production", "Process control" and "The added value of project". "Quality of production" is an abstract concept that could not be judged directly, and therefore is decomposed into three detailed concepts: "Scale and importance", "Technique" and "Theoretical value and level of innovation". If these concepts are still too abstract to be evaluated directly, they should be decomposed into more detailed factors until they could be directly evaluated. In our research, "Quality of production" is a hierarchical structure of three levels shown in Fig. 2.

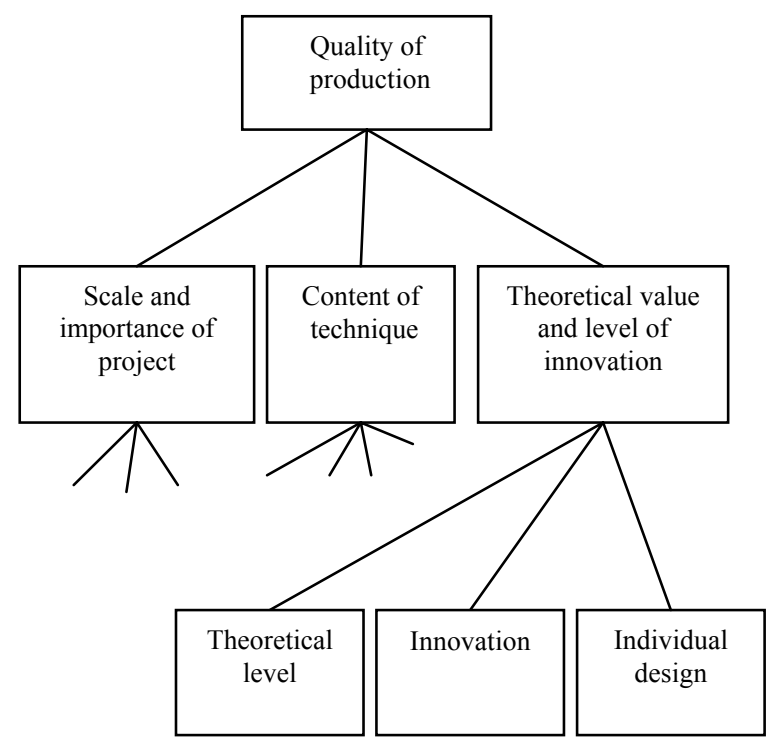

Fig. 2. The hierarchical structure for quality of production in "R\&D projects evaluation system"

In the above evaluation framework, "Theoretical level", "Innovation" and "Individual design" are referred to as three basic factors associated with its upper attribute "Theoretical value and level of innovation" in the second level of the hierarchy.

Based on this decomposition progress, we obtain the complete three-level hierarchy of attributes for evaluation of strategic R\&D projects as shown in Table 1. Seventeen basic attributes for the evaluation of $R \& D$ projects are identified. Eleven of them are qualitative and the rest are quantitative. 
Table 1. The standard table for checkout and evaluation system of strategic R\&D projects

\begin{tabular}{|c|c|c|}
\hline General attributes & Attributes in the second level & Factors in the lowest level(contents of evaluation) \\
\hline \multirow{10}{*}{ Quality of production } & \multirow{3}{*}{ Scale and importance of project } & Workload $C_{1}$ \\
\hline & & Origin of members $C_{2}$ \\
\hline & & Importance of project $C_{3}$ \\
\hline & \multirow{4}{*}{ Content of technique } & Complexity of critical technique $C_{4}$ \\
\hline & & Cost performance of product $C_{5}$ \\
\hline & & Reliability of product $C_{6}$ \\
\hline & & Economy $C_{7}$ \\
\hline & \multirow{3}{*}{$\begin{array}{l}\text { Theoretical value and level of } \\
\text { innovation }\end{array}$} & Theoretical level of project $C_{8}$ \\
\hline & & Degree of innovation $C_{9}$ \\
\hline & & Ratio of individual design $C_{10}$ \\
\hline \multirow{3}{*}{ Process control } & \multicolumn{2}{|r|}{ Quality of project $C_{11}$} \\
\hline & \multicolumn{2}{|r|}{ Delayed time for project $C_{12}$} \\
\hline & \multicolumn{2}{|r|}{ Investment $C_{13}$} \\
\hline \multirow{4}{*}{$\begin{array}{l}\text { Added value of } \\
\text { project }\end{array}$} & \multirow{3}{*}{ Project team } & Construction of regulation system of project team $C_{14}$ \\
\hline & & Routine operational management documents $C_{15}$ \\
\hline & & Management documents about $\mathrm{R} \& \mathrm{D}$ process of product $C_{16}$ \\
\hline & Continuity of technique & Accumulation and continuity of technique $C_{17}$ \\
\hline
\end{tabular}

Considering the complexity of handling multiple attributes simultaneously, it is important to get a group of experts involved for assigning attributes' weights, who may have different backgrounds and expertise and may represent conflicting interests. It is therefore necessary to achieve group judgments from individual experts' estimation. The group analytic hierarchy process (GAHP) is a method for generating the aggregated weights of attributes from the judgments given by a group of experts.

In the process of eliciting group judgements, paired comparisons between every two attributes are provided by each expert to construct his or her judgment matrix. Then the judgment matrices of all experts are aggregated to form an overall judgment matrix. There are several approaches that can be used for the aggregation of paired comparison matrices, for instance, the ideal synthesis matrix in a group context, the additive convex set and Hadamard convex set of judgmental matrices. ${ }^{29}$ These approaches can minimize the impact of inconsistence among individual expert judgments. In this paper, Hadamard convex set of judgmental matrices is implemented to construct an overall judgment matrix. Then, the analytic hierarchy process (AHP) approach is applied to calculate the weight of each attribute. The whole process is referred to as a generalized AHP approach, or GAHP. ${ }^{30}$
200 questionnaires for comparing the importance of the attributes listed in table 1 were sent to the members of the R\&D centre and the relevant leaders of the company, from which 172 questionnaires were returned with 5 completely useless and 10 partly useless. Based on the 172 questionnaires, the GAHP approach is used to calculate the weights of attributes, and the result is as follows. The weights of the attributes in the first level are given by

$$
\omega_{1}=0.3957, \omega_{2}=0.3617, \omega_{3}=0.2426 ;
$$

The weights of the attributes in the second level are given by

$$
\begin{gathered}
\omega_{1,1}=0.2886, \omega_{1,2}=0.3845, \omega_{1,3}=0.3269 ; \\
\omega_{2,1}=0.4919, \omega_{2,2}=0.2175, \omega_{2,3}=0.2906 ; \\
\omega_{3,1}=0.4794, \omega_{3,2}=0.5206 .
\end{gathered}
$$

The weights of the attributes in the third level are given by

$$
\begin{aligned}
& \omega_{1,1,1}= 0.2247, \omega_{1,1,2}=0.2438, \omega_{1,1,3}=0.5315 ; \\
& \omega_{1,2,1}=0.1319, \omega_{1,2,2}=0.2692, \\
& \omega_{1,2,3}=0.3781, \omega_{1,2,4}=0.2208 ; \\
& \omega_{1,3,1}= 0.2446, \omega_{1,3,2}=0.4050, \omega_{1,3,3}=0.3504 ; \\
& \omega_{3,1,1}=0.2842, \omega_{3,1,2}=0.3430, \omega_{3,1,3}=0.3728 .
\end{aligned}
$$

The weights listed above represent the relative importance of each attribute with respect to its upper level attribute. We can obtain the absolute weight of each attribute by simple calculation. And the weights of the seventeen basic attributes are given as follows: 
$\mathrm{w}_{1}=0.03, \mathrm{w}_{2}=0.03, \mathrm{w}_{3}=0.06, \mathrm{w}_{4}=0.03, \mathrm{w}_{5}=0.04$, $\mathrm{w}_{6}=0.06, \mathrm{w}_{7}=0.03, \mathrm{w}_{8}=0.03, \mathrm{w}_{9}=0.05, \mathrm{w}_{10}=0.04$, $\mathrm{w}_{11}=0.18, \mathrm{w}_{12}=0.07, \mathrm{w}_{13}=0.1, \mathrm{w}_{14}=0.03, \mathrm{w}_{15}=0.04$, $\mathrm{w}_{16}=0.05, \mathrm{w}_{17}=0.13$.

The value of each weight listed above is rounded to make the evaluation simpler, with some small adjustments so that the sum of weights equals to 1 .

\subsection{The acquisition of evaluation information}

The four strategic R\&D projects to be evaluated are Light Trailers $\left(A_{1}\right)$, Heavy Trailers $\left(A_{2}\right)$, Multi-Purpose Vehicles $\left(A_{3}\right)$ and Small Recreation Vehicles $\left(A_{4}\right)$.

\subsubsection{The evaluation of strategic $R \& D$ projects with respect to quantitative attributes}

There are six quantitative attributes among the seventeen basic ones, which are Workload $\left(C_{1}\right)$, Origin of members $\left(C_{2}\right)$, Reliability of product $\left(C_{6}\right)$, Ratio of individual design $\left(C_{10}\right)$, Delayed time for project $\left(C_{12}\right)$ and Investment of project $\left(C_{13}\right)$.

\section{$C_{1}$ : Workload}

Workload is evaluated by the expected completion time of each project, which is associated with the scale and importance of production. It is considered to be the worst in terms of workload if a project is not complex and is planned to be completed within only one month, and a project is assessed to be better if it is complex and is planned for more time. So it is a benefit attribute.

$C_{2}$ : Origin of members

The members of a project may come from different departments. A project is considered to be more important if its members are from more departments, so it is also a benefit attribute.

$C_{6}$ : Reliability of products

It is evaluated by the number of broken-down products in every 100 products in three months.

$C_{10}$ : Ratio of individual design

If a product is completely designed by the members of the company, it is assessed the highest grade. The higher the ratio of individual design, the better the evaluation grade.

$C_{12}$ : Delayed time for project

It is evaluated by the delay time of projects. If a R\&D project is completed ahead of its schedule or on time, then as far as completion time is concerned, the project is evaluated as the highest grade. So it is a cost attribute.

\section{$C_{13}$ : Investment of projects}

It is evaluated by the percentage of overspending compared with the budget. A project would be assessed to be best if there is cost saving or no overspending; otherwise it will be assessed to different grades in accordance with its overspending percentage. It is also a cost attribute.

The performance ratings of $\mathrm{R} \& \mathrm{D}$ projects with respect to the six quantitative attributes are shown in Table 2.

Table 2. Original evaluation of strategic R\&D projects in quantitative attributes

\begin{tabular}{|c|c|c|c|c|c|c|}
\hline & Quantitative \\
Altributes & $\begin{array}{c}C_{1} \\
\text { (Mo } \\
\text { nths) }\end{array}$ & $C_{2}$ & $C_{6}$ & $\begin{array}{c}C_{10} \\
(\%)\end{array}$ & $\begin{array}{c}C_{12} \\
(\mathrm{Mon} \\
\text { ths })\end{array}$ & $\begin{array}{c}C_{13} \\
(\%)\end{array}$ \\
\cline { 2 - 7 } & 0.03 & 0.03 & 0.06 & 0.04 & 0.07 & 0.1 \\
\hline Light Trailer & 3 & 4 & unknown & $70 \sim 80$ & 2 & 0 \\
\hline Heavy Trailer & 3 & 4 & unknown & $80 \sim 90$ & 0 & 0 \\
\hline MPV & 8 & 4 & unknown & $70 \sim 80$ & 0 & 0 \\
\hline SRV & 10 & 4 & unknown & $70 \sim 80$ & 0 & 0 \\
\hline
\end{tabular}

5.2.2. The evaluation of strategic $R \& D$ projects with respect to qualitative attributes

The rest eleven attributes are qualitative, they are evaluated as follows:

$C_{3}$ : Importance of project

The importance of project is evaluated by the effect of a project on the factory, such as to fill a gap in the product structure and have strategic significance to the factory, to fill a gap in single product, to make an accommodation, etc.

$C_{4}$ : Complexity of critical technique

The evaluation grades of $C_{4}$ should be marked off according to the complexity of technology applied in the product. The more complex the technology applied, the higher the evaluation grade would be assumed.

$C_{5}$ : Cost performance of product

Six products of the same type are selected to make comparison evaluation of cost performance. For example, when heavy trailer is evaluated with respect to cost performance, six heavy trailers of the similar type (considering weight, oil consumption and so on) in other car factories are selected. Then the evaluation is obtained by comparing the heavy trailer with the selected six heavy trailers with respect to cost performance. 


\section{$C_{7}$ : Economy}

It is evaluated by comparing the fuel consumption of products with other similar type of vehicles.

$C_{8}$ : Theoretical level of project

It is evaluated by the theoretical level reflected from the R\&D projects.

$C_{9}$ : Degree of innovation

It is evaluated by the innovation degree reflected from the $R \& D$ projects.

$C_{11}$ : Quality of project

According to the plan of projects, check the performance of projects including the achievement of technique criteria and the standardization of manipulation. It would be given high evaluation grade if all technical criteria reach or exceed the expected standard. While a project would be marked poor if quality accident occurs.

$C_{14}$ : Construction of regulation system of project team

It is evaluated by the maturity and the management effect of regulation documents.

$C_{15}$ : Routine operational management

It is evaluated by the maturity and the management effect of routine management documents.
$C_{16}$ : Management documents about $\mathrm{R} \& \mathrm{D}$ process of products

It is evaluated by the maturity and the management effect of management documents about $R \& D$ process of products.

$C_{17}$ : Accumulation and continuity of technique

It is evaluated by the possible contribution for future projects. A project would be evaluated as high grade if its technique or theory has great significance for future projects.

The evaluation of R\&D projects with respect to qualitative attributes is given by five experts: one managing director, two designers and two technicians. The relative importance of each expert is managed according to the importance observed through interviews with the manager, and the weights of experts are determined as $0.25,0.2,0.2,0.2$ and 0.15 .

There are nine linguistic terms for experts to evaluate: $S_{0}=$ extremely poor, $S_{1}=$ very poor, $S_{2}=$ poor, $S_{3}=$ slightly poor, $S_{4}=$ fair, $S_{5}=$ slightly good, $S_{6}=$ good, $S_{7}=$ very good, $S_{8}=$ extremely good. Uncertain evaluation is allowed because of the complexity of this evaluation problem, and the evaluation information given by experts is shown in table 3 .

Table 3. Original evaluation of strategic R\&D projects on qualitative attributes

\begin{tabular}{|c|c|c|c|c|c|c|c|c|c|c|c|c|}
\hline \multirow{2}{*}{\multicolumn{2}{|c|}{ Qualitative Attributes }} & $C_{3}$ & $C_{4}$ & $C_{5}$ & $C_{7}$ & $C_{8}$ & $C_{9}$ & $C_{11}$ & $C_{14}$ & $C_{15}$ & $C_{16}$ & $C_{17}$ \\
\hline & & 0.06 & 0.03 & 0.04 & 0.03 & 0.03 & 0.05 & 0.18 & 0.03 & 0.04 & 0.05 & 0.13 \\
\hline \multirow{4}{*}{$E_{1}$} & Light trailer & {$\left[s_{4}, s_{6}\right]$} & {$\left[s_{5}, s_{7}\right]$} & {$\left[s_{6}, s_{8}\right]$} & {$\left[s_{7}, s_{8}\right]$} & {$\left[s_{5}, s_{7}\right]$} & {$\left[s_{3}, s_{5}\right]$} & {$\left[s_{6}, s_{8}\right]$} & {$\left[s_{4}, s_{5}\right]$} & {$\left[s_{4}, s_{6}\right]$} & {$\left[s_{4}, s_{6}\right]$} & {$\left[s_{6}, s_{7}\right]$} \\
\hline & Heavy Trailer & {$\left[s_{7}, s_{8}\right]$} & {$\left[s_{7}, s_{8}\right]$} & {$\left[s_{6}, s_{7}\right]$} & {$\left[s_{5}, s_{7}\right]$} & {$\left[s_{6}, s_{7}\right]$} & {$\left[s_{4}, s_{6}\right]$} & {$\left[s_{7}, s_{8}\right]$} & {$\left[s_{5}, s_{7}\right]$} & {$\left[s_{6}, s_{7}\right]$} & {$\left[s_{5}, s_{7}\right]$} & {$\left[s_{7}, s_{8}\right]$} \\
\hline & MPV & {$\left[s_{5}, s_{7}\right]$} & {$\left[s_{6}, s_{7}\right]$} & {$\left[s_{6}, s_{8}\right]$} & {$\left[s_{6}, s_{7}\right]$} & {$\left[s_{7}, s_{8}\right]$} & {$\left[s_{5}, s_{7}\right]$} & {$\left[s_{5}, s_{7}\right]$} & {$\left[s_{4}, s_{6}\right]$} & {$\left[s_{6}, s_{7}\right]$} & {$\left[s_{6}, s_{8}\right]$} & {$\left[s_{6}, s_{8}\right]$} \\
\hline & SRV & {$\left[s_{6}, s_{8}\right]$} & {$\left[s_{6}, s_{8}\right]$} & {$\left[s_{5}, s_{6}\right]$} & {$\left[s_{4}, s_{6}\right]$} & {$\left[s_{6}, s_{8}\right]$} & {$\left[s_{3}, s_{5}\right]$} & {$\left[s_{6}, s_{8}\right]$} & {$\left[s_{4}, s_{6}\right]$} & {$\left[s_{5}, s_{6}\right]$} & {$\left[s_{5}, s_{7}\right]$} & {$\left[s_{6}, s_{8}\right]$} \\
\hline \multirow{4}{*}{$E_{2}$} & Light trailer & {$\left[s_{4}, s_{6}\right]$} & {$\left[s_{5}, s_{6}\right]$} & {$\left[s_{6}, s_{7}\right]$} & {$\left[s_{6}, s_{8}\right]$} & {$\left[s_{4}, s_{6}\right]$} & {$\left[s_{0}, s_{2}\right]$} & {$\left[s_{6}, s_{7}\right]$} & {$\left[s_{3}, s_{4}\right]$} & {$\left[s_{4}, s_{6}\right]$} & {$\left[s_{4}, s_{6}\right]$} & {$\left[s_{6}, s_{7}\right]$} \\
\hline & Heavy Trailer & {$\left[s_{6}, s_{8}\right]$} & {$\left[s_{6}, s_{8}\right]$} & {$\left[s_{5}, s_{7}\right]$} & {$\left[s_{5}, s_{6}\right]$} & {$\left[s_{6}, s_{7}\right]$} & {$\left[s_{2}, s_{4}\right]$} & {$\left[s_{6}, s_{8}\right]$} & {$\left[s_{4}, s_{6}\right]$} & {$\left[s_{5}, s_{7}\right]$} & {$\left[s_{5}, s_{7}\right]$} & {$\left[s_{6}, s_{8}\right]$} \\
\hline & MPV & {$\left[s_{5}, s_{7}\right]$} & {$\left[s_{6}, s_{7}\right]$} & {$\left[s_{6}, s_{7}\right]$} & {$\left[s_{5}, s_{7}\right]$} & {$\left[s_{6}, s_{7}\right]$} & {$\left[s_{3}, s_{5}\right]$} & {$\left[s_{5}, s_{7}\right]$} & {$\left[s_{3}, s_{5}\right]$} & {$\left[s_{5}, s_{7}\right]$} & {$\left[s_{6}, s_{7}\right]$} & {$\left[s_{6}, s_{7}\right]$} \\
\hline & SRV & {$\left[s_{6}, s_{7}\right]$} & {$\left[s_{6}, s_{7}\right]$} & {$\left[s_{4}, s_{6}\right]$} & {$\left[s_{4}, s_{5}\right]$} & {$\left[s_{6}, s_{8}\right]$} & {$\left[s_{1}, s_{3}\right]$} & {$\left[s_{6}, s_{7}\right]$} & {$\left[s_{3}, s_{4}\right]$} & {$\left[s_{4}, s_{6}\right]$} & {$\left[s_{5}, s_{7}\right]$} & {$\left[s_{6}, s_{7}\right]$} \\
\hline \multirow{4}{*}{$E_{3}$} & Light trailer & {$\left[s_{3}, s_{5}\right]$} & {$\left[s_{4}, s_{6}\right]$} & {$\left[s_{6}, s_{7}\right]$} & {$\left[s_{7}, s_{8}\right]$} & {$\left[s_{4}, s_{6}\right]$} & {$\left[s_{1}, s_{2}\right]$} & {$\left[s_{6}, s_{7}\right]$} & {$\left[s_{3}, s_{5}\right]$} & {$\left[s_{4}, s_{5}\right]$} & {$\left[s_{4}, s_{6}\right]$} & {$\left[s_{5}, s_{6}\right]$} \\
\hline & Heavy Trailer & {$\left[s_{5}, s_{7}\right]$} & {$\left[s_{6}, s_{7}\right]$} & {$\left[s_{5}, s_{7}\right]$} & {$\left[s_{6}, s_{7}\right]$} & {$\left[s_{5}, s_{7}\right]$} & {$\left[s_{2}, s_{4}\right]$} & {$\left[s_{7}, s_{8}\right]$} & {$\left[s_{5}, s_{6}\right]$} & {$\left[s_{5}, s_{7}\right]$} & {$\left[s_{6}, s_{7}\right]$} & {$\left[s_{5}, s_{7}\right]$} \\
\hline & MPV & {$\left[s_{4}, s_{6}\right]$} & {$\left[s_{5}, s_{7}\right]$} & {$\left[s_{5}, s_{7}\right]$} & {$\left[s_{6}, s_{7}\right]$} & {$\left[s_{5}, s_{7}\right]$} & {$\left[s_{3}, s_{4}\right]$} & {$\left[s_{5}, s_{7}\right]$} & {$\left[s_{4}, s_{6}\right]$} & {$\left[s_{5}, s_{7}\right]$} & {$\left[s_{6}, s_{8}\right]$} & {$\left[s_{5}, s_{6}\right]$} \\
\hline & SRV & {$\left[s_{5}, s_{7}\right]$} & {$\left[s_{6}, s_{7}\right]$} & {$\left[s_{4}, s_{6}\right]$} & {$\left[s_{5}, s_{6}\right]$} & {$\left[s_{6}, s_{7}\right]$} & {$\left[s_{1}, s_{3}\right]$} & {$\left[s_{6}, s_{7}\right]$} & {$\left[s_{4}, s_{6}\right]$} & {$\left[s_{4}, s_{7}\right]$} & {$\left[s_{5}, s_{7}\right]$} & {$\left[s_{5}, s_{6}\right]$} \\
\hline \multirow{4}{*}{$E_{4}$} & Light trailer & {$\left[s_{5}, s_{6}\right]$} & {$\left[s_{5}, s_{6}\right]$} & {$\left[s_{5}, s_{7}\right]$} & {$\left[s_{6}, s_{8}\right]$} & {$\left[s_{5}, s_{6}\right]$} & {$\left[s_{0}, s_{1}\right]$} & {$\left[s_{4}, s_{5}\right]$} & {$\left[s_{3}, s_{5}\right]$} & {$\left[s_{4}, s_{6}\right]$} & {$\left[s_{3}, s_{5}\right]$} & {$\left[s_{5}, s_{7}\right]$} \\
\hline & Heavy Trailer & {$\left[s_{6}, s_{8}\right]$} & {$\left[s_{6}, s_{8}\right]$} & {$\left[s_{5}, s_{7}\right]$} & {$\left[s_{5}, s_{7}\right]$} & {$\left[s_{6}, s_{7}\right]$} & {$\left[s_{3}, s_{4}\right]$} & {$\left[s_{5}, s_{7}\right]$} & {$\left[s_{5}, s_{7}\right]$} & {$\left[s_{6}, s_{7}\right]$} & {$\left[s_{5}, s_{6}\right]$} & {$\left[s_{6}, s_{8}\right]$} \\
\hline & MPV & {$\left[s_{5}, s_{6}\right]$} & {$\left[s_{6}, s_{7}\right]$} & {$\left[s_{6}, s_{7}\right]$} & {$\left[s_{6}, s_{7}\right]$} & {$\left[s_{6}, s_{8}\right]$} & {$\left[s_{3}, s_{5}\right]$} & {$\left[s_{3}, s_{5}\right]$} & {$\left[s_{4}, s_{5}\right]$} & {$\left[s_{6}, s_{7}\right]$} & {$\left[s_{5}, s_{7}\right]$} & {$\left[s_{5}, s_{7}\right]$} \\
\hline & SRV & {$\left[s_{6}, s_{7}\right]$} & {$\left[s_{6}, s_{7}\right]$} & {$\left[s_{5}, s_{6}\right]$} & {$\left[s_{4}, s_{6}\right]$} & {$\left[s_{6}, s_{8}\right]$} & {$\left[s_{2}, s_{4}\right]$} & {$\left[s_{4}, s_{6}\right]$} & {$\left[s_{4}, s_{5}\right]$} & {$\left[s_{5}, s_{6}\right]$} & {$\left[s_{5}, s_{6}\right]$} & {$\left[s_{6}, s_{7}\right]$} \\
\hline \multirow{4}{*}{$E_{5}$} & Light trailer & {$\left[s_{4}, s_{6}\right]$} & {$\left[s_{4}, s_{5}\right]$} & {$\left[s_{6}, s_{7}\right]$} & {$\left[s_{7}, s_{8}\right]$} & {$\left[s_{4}, s_{6}\right]$} & {$\left[s_{1}, s_{3}\right]$} & {$\left[s_{5}, s_{7}\right]$} & {$\left[s_{2}, s_{4}\right]$} & {$\left[s_{4}, s_{6}\right]$} & {$\left[s_{4}, s_{5}\right]$} & {$\left[s_{5}, s_{7}\right]$} \\
\hline & Heavy Trailer & {$\left[s_{6}, s_{7}\right]$} & {$\left[s_{5}, s_{7}\right]$} & {$\left[s_{5}, s_{7}\right]$} & {$\left[s_{6}, s_{7}\right]$} & {$\left[s_{5}, s_{7}\right]$} & {$\left[s_{2}, s_{4}\right]$} & {$\left[s_{6}, s_{8}\right]$} & {$\left[s_{4}, s_{6}\right]$} & {$\left[s_{5}, s_{7}\right]$} & {$\left[s_{5}, s_{7}\right]$} & {$\left[s_{6}, s_{7}\right]$} \\
\hline & MPV & {$\left[s_{5}, s_{6}\right]$} & {$\left[s_{5}, s_{6}\right]$} & {$\left[s_{6}, s_{7}\right]$} & {$\left[s_{6}, s_{7}\right]$} & {$\left[s_{6}, s_{7}\right]$} & {$\left[s_{3}, s_{5}\right]$} & {$\left[s_{5}, s_{6}\right]$} & {$\left[s_{3}, s_{5}\right]$} & {$\left[s_{5}, s_{7}\right]$} & {$\left[s_{6}, s_{7}\right]$} & {$\left[s_{6}, s_{7}\right]$} \\
\hline & SRV & {$\left[s_{6}, s_{7}\right]$} & {$\left[s_{5}, s_{7}\right]$} & {$\left[s_{4}, s_{6}\right]$} & {$\left[s_{5}, s_{6}\right]$} & {$\left[s_{6}, s_{8}\right]$} & {$\left[s_{1}, s_{3}\right]$} & {$\left[s_{5}, s_{7}\right]$} & {$\left[s_{3}, s_{5}\right]$} & {$\left[s_{5}, s_{6}\right]$} & {$\left[s_{5}, s_{7}\right]$} & {$\left[s_{6}, s_{7}\right]$} \\
\hline
\end{tabular}




\subsubsection{The acquisition of decision matrices}

As the data on attribute $C_{6}$ are absent, it can be seemed that all the alternatives are evaluated as $\left[s_{0}, s_{8}\right]$ with respect to $C_{6}$. Besides $C_{6}$, there are other attributes which take the same value for each alternative, such as $C_{2}$ and $C_{13}$. We wipe those attributes off before the TOPSIS process. Then using the mapping $\varphi$, we get the numerical decision matrices. For example, the numerical decision matrix of expert $E_{1}$ is

$$
\begin{aligned}
& T^{(1)}=\left[\begin{array}{ccccccc}
3 & {[4,6]} & {[5,7]} & {[6,8]} & {[7,8]} & {[5,7]} & {[3,5]} \\
3 & {[7,8]} & {[7,8]} & {[6,7]} & {[5,7]} & {[6,7]} & {[4,6]} \\
8 & {[5,7]} & {[6,7]} & {[6,8]} & {[6,7]} & {[7,8]} & {[5,7]} \\
10 & {[6,8]} & {[6,8]} & {[5,6]} & {[4,6]} & {[6,8]} & {[3,5]}
\end{array}\right. \\
& {\left[\begin{array}{lllllll}
{[70,80]} & {[6,8]} & 2 & {[4,5]} & {[4,6]} & {[4,6]} & {[6,7]}
\end{array}\right.} \\
& {[80,90] \quad[7,8] \quad 0 \quad[5,7] \quad[6,7] \quad[5,7] \quad[7,8]} \\
& {\left[\begin{array}{lllllll}
{[70,80]} & {[5,7]} & 0 & {[4,6]} & {[6,7]} & {[6,8]} & {[6,8]}
\end{array}\right.} \\
& {[70,80] \quad[6,8] \quad 0 \quad[4,6] \quad[5,6] \quad[5,7] \quad[6,8]}
\end{aligned}
$$

\subsection{Evaluation results and analysis}

\begin{tabular}{|c|c|c|}
\hline & $\begin{array}{c}\text { Relative closeness } \\
\text { coefficients }\end{array}$ & Ranking result \\
\hline$A_{1}$ & {$[0.0957,0.1652]$} & \multirow{4}{*}{$A_{2} \succ A_{4} \succ A_{3} \succ A_{1}$} \\
\hline$A_{2}$ & {$[0.8061,0.8243]$} & \\
\hline$A_{3}$ & {$[0.7429,0.7717]$} & \\
\hline$A_{4}$ & {$[0.7810,0.7971]$} & \\
\hline
\end{tabular}

The proposed approach is applied to evaluating the four strategic R\&D projects. A MATLAB program is designed to implement the approach and the result is shown in table 4 .

Table 4. Ranking result of strategic R\&D projects

From Table 4, we can see that the relative closeness coefficients of the four strategic $R \& D$ projects are not overlapping, so the ranking result of the four alternatives is $A_{2} \succ A_{4} \succ A_{3} \succ A_{1}$.

\subsection{Sensitivity analysis}

The sensitivity analysis of weights and evaluation intervals will be conducted respectively in this section.

\subsubsection{Sensitivity analysis of weights}

The combined weights calculated using the GAHP method represent the aggregated opinions of all experts involved in the investigation, while the sensitivity analysis of weights should be conducted based on the above combined weights to reflect the views of individual expert or department. In this case study, GAHP is used to process the data collected from two of the three departments, and two different pieces of weights are generated. The following are the rounded values of the weights calculated using GAHP. The weights calculated using the information collected from the marketing department are given as follows. The weights of the attributes in the first level are given by

$$
\omega_{1}=0.40, \omega_{2}=0.44, \omega_{3}=0.16
$$

The weights of the attributes in the second level are given by

$$
\begin{gathered}
\omega_{1,1}=0.30, \omega_{1,2}=0.60, \omega_{1,3}=0.10 ; \\
\omega_{2,1}=0.11, \omega_{2,2}=0.53, \omega_{2,3}=0.36 ; \\
\omega_{3,1}=0.45, \omega_{3,2}=0.55 .
\end{gathered}
$$

The weights of the attributes in the third level are given by

$$
\begin{gathered}
\omega_{1,1,1}=0.50, \omega_{1,1,2}=0.25, \omega_{1,1,3}=0.25 ; \\
\omega_{1,2,1}=0.13, \omega_{1,2,2}=0.46 \\
\omega_{1,2,3}=0.11, \omega_{1,2,4}=0.30 \\
\omega_{1,3,1}=0.25, \omega_{1,3,2}=0.42, \omega_{1,3,3}=0.33 ; \\
\omega_{3,1,1}=0.25, \omega_{3,1,2}=0.35, \omega_{3,1,3}=0.40 .
\end{gathered}
$$

So the weights of the seventeen basic attributes are obtained as follows:

$$
\begin{gathered}
\mathrm{w}_{1}=0.06, \mathrm{w}_{2}=0.03, \mathrm{w}_{3}=0.03, \mathrm{w}_{4}=0.03, \mathrm{w}_{5}=0.11, \\
\mathrm{w}_{6}=0.03, \mathrm{w}_{7}=0.07, \mathrm{w}_{8}=0.01, \mathrm{w}_{9}=0.02, \\
\mathrm{w}_{10}=0.01, \mathrm{w}_{11}=0.05, \mathrm{w}_{12}=0.23, \mathrm{w}_{13}=0.16, \\
\mathrm{w}_{14}=0.02, \mathrm{w}_{15}=0.02, \mathrm{w}_{16}=0.03, \mathrm{w}_{17}=0.09 .
\end{gathered}
$$

The ranking result is shown in table 5 .

Table 5. Ranking result of strategic $R \& D$ projects using the weights generated for marketing department

\begin{tabular}{|c|c|c|}
\hline & $\begin{array}{c}\text { Relative closeness } \\
\text { coefficients }\end{array}$ & Ranking result \\
\hline$A_{1}$ & {$[0.0664,0.0735]$} & \multirow{3}{*}{$A_{3} \succ A_{4} \succ A_{2} \succ A_{1}$} \\
\hline$A_{2}$ & {$[0.8759,0.8782]$} & \\
\hline$A_{3}$ & {$[0.9457,0.9476]$} & \\
\hline$A_{4}$ & {$[0.9228,0.9269]$} & \\
\hline
\end{tabular}

The weights calculated using the information collected from the manufacturing department is as follows. The weights of the attributes in the first level are given by

$$
\omega_{1}=0.47, \omega_{2}=0.34, \omega_{3}=0.19
$$

The weights of the attributes in the second level are given by 


$$
\begin{aligned}
& \omega_{1,1}=0.41, \omega_{1,2}=0.35, \omega_{1,3}=0.24 ; \\
& \omega_{2,1}=0.60, \omega_{2,2}=0.28, \omega_{2,3}=0.12 ; \\
& \omega_{3,1}=0.49, \omega_{3,2}=0.51 .
\end{aligned}
$$

The weights of the attributes in the third level are given by

$$
\begin{gathered}
\omega_{1,1,1}=0.52, \omega_{1,1,2}=0.23, \omega_{1,1,3}=0.25 ; \\
\omega_{1,2,1}=0.22, \omega_{1,2,2}=0.30 ; \\
\omega_{1,2,3}=0.17, \omega_{1,2,4}=0.31 ; \\
\omega_{1,3,1}=0.28, \omega_{1,3,2}=0.40, \omega_{1,3,3}=0.32 ; \\
\omega_{3,1,1}=0.34, \omega_{3,1,2}=0.39, \omega_{3,1,3}=0.27 .
\end{gathered}
$$

So the weights of the seventeen basic attributes are obtained as follows:

$$
\begin{gathered}
\mathrm{w}_{1}=0.1, \mathrm{w}_{2}=0.04, \mathrm{w}_{3}=0.05, \mathrm{w}_{4}=0.04, \mathrm{w}_{5}=0.05, \\
\mathrm{w}_{6}=0.03, \mathrm{w}_{7}=0.05, \mathrm{w}_{8}=0.03, \mathrm{w}_{9}=0.04, \\
\mathrm{w}_{10}=0.04, \mathrm{w}_{11}=0.2, \mathrm{w}_{12}=0.1, \mathrm{w}_{13}=0.04, \\
\mathrm{w}_{14}=0.03, \mathrm{w}_{15}=0.04, \mathrm{w}_{16}=0.02, \mathrm{w}_{17}=0.1 .
\end{gathered}
$$

The ranking result is shown as follows:

Table 6. Ranking result of strategic R\&D projects using the weights calculated for manufacturing department

\begin{tabular}{|c|c|c|}
\hline & $\begin{array}{c}\text { Relative closeness } \\
\text { coefficients }\end{array}$ & Ranking result \\
\hline$A_{1}$ & {$[0.0898,0.1370]$} & \multirow{3}{*}{$A_{4} \succ A_{3} \succ A_{2} \succ A_{1}$} \\
\hline$A_{2}$ & {$[0.6606,0.6707]$} & \\
\hline$A_{3}$ & {$[0.7763,0.7969]$} & \\
\hline$A_{4}$ & {$[0.8435,0.8554]$} & \\
\hline
\end{tabular}

It is observed that light trailer $\left(A_{1}\right)$ is ranked the worst among the four strategic R\&D projects no matter whether the ranking is based on the weights calculated for the marketing department, the manufacturing department or all departments, Heavy trailer $\left(A_{2}\right)$ is ranked the best among these four R\&D projects based on the weights for all departments, MPV $\left(A_{3}\right)$ is ranked the best based on the weights for marketing department, while SRV $\left(A_{4}\right)$ is ranked the best based on the weights for manufacturing department. The ranking results are inconsistent due to different opinions about the importance of attributes from people in different departments. So it is significant to construct several sets of weights from different departments to support the decision making process.

\subsubsection{Sensitivity analysis of evaluation intervals}

In the proposed MAGDM model, the form of information given by experts can be uncertain linguistic variable, which is an interval of linguistic evaluation. If an expert is somewhat sure about an alternative, the span of his linguistic evaluation intervals may be small. However, the span of linguistic evaluation intervals may be large if an expert knows little about some alternative or attribute. Although uncertain evaluations are common in practice because of the limitation of knowledge and the complexity of decision problems, it is not helpful in decision making if a linguistic evaluation interval become too large. Therefore, whenever there is uncertain evaluation interval, it is necessary to conduct sensitivity analysis to find the range of linguistic evaluation intervals which could preserve the ranking order of alternatives.

We try to extend all linguistic evaluation intervals half grade a time on both sides (not overstep the lower limit $s_{0}$ and the upper limit $s_{8}$ ) until the ranking result changes. For example, linguistic evaluation interval $\left[s_{5}\right.$, $\left.s_{7}\right]$ is first extended half grade on both sides to $\left[s_{4.5}\right.$, $\left.s_{7.5}\right]$, then is extended one more time to $\left[s_{4}, s_{8}\right]$, and so on.

We first extend all linguistic evaluation intervals half grade on both sides and keep the values on quantitative attributes unaltered. After the operation of mapping $\varphi$, we get new decision matrices. For example, the new decision matrix given by expert $E_{1}$ is as follows:

$$
\begin{aligned}
& {\left[\begin{array}{lllllll}
3 & {[3,7]} & {[4,8]} & {[5,8]} & {[6,8]} & {[4,8]} & {[2,6]}
\end{array}\right.} \\
& T^{(1)^{\prime}}=\mid \begin{array}{lllllll}
3 & {[6,8]} & {[6,8]} & {[5,8]} & {[4,8]} & {[5,8]} & {[3,7]} \\
8 & {[4,8]} & {[5,8]} & {[5,8]} & {[5,8]} & {[6,8]} & {[4,8]}
\end{array} \\
& 8 \quad[4,8] \quad[5,8] \quad[5,8] \quad[5,8] \quad[6,8] \quad[4,8] \\
& \begin{array}{llllllll}
10 & {[5,8]} & {[5,8]} & {[4,7]} & {[3,7]} & {[5,8]} & {[2,6]}
\end{array} \\
& \left.\begin{array}{lllllll}
{[70,80]} & {[5,8]} & 2 & {[3,6]} & {[3,7]} & {[3,7]} & {[5,8]} \\
{[80,90]} & {[6,8]} & 0 & {[4,8]} & {[5,8]} & {[4,8]} & {[6,8]} \\
{[70,80]} & {[4,8]} & 0 & {[3,7]} & {[5,8]} & {[5,8]} & {[5,8]} \\
{[70,80]} & {[5,8]} & 0 & {[3,7]} & {[4,7]} & {[4,8]} & {[5,8]}
\end{array}\right] .
\end{aligned}
$$

The ranking result under the new evaluation information can be obtained by running the programme, which is $A_{2} \succ A_{4} \succ A_{3} \succ A_{1}$. Then we extend the linguistic evaluation intervals once again, and find the ranking result changes to $A_{4} \succ A_{2} \succ A_{3} \succ A_{1}$. So we come to the conclusion that the ranking result of the four R\&D projects will not change if the linguistic evaluation intervals of each expert is extended no more than one grades on both sides. 


\section{Conclusions}

This paper presented an extended TOPSIS approach which is suitable for solving the MAGDM problems in environments combining numerical with uncertain linguistic information. A transformation function is defined to deal with decision information in different formats. In the extended TOPSIS procedure, the distance between ndimensional interval numbers is defined to measure the closeness degree of alternatives, which is in the form of interval numbers and is considered to keep more information than crisp values. A real problem of evaluation of strategic R\&D projects was carried out to exemplify the proposed approach. The sensitivity analysis of the case was also conducted.

In this paper, the preliminary sensitivity analysis of weights and evaluation intervals were conducted. In future research, more comprehensive analyses on evaluation intervals or uncertain weights need to be conducted to support more informative decision making.

\section{Acknowledgements}

We would like to express our thanks to the support of the Key Program of National Natural Science Foundation of China (70631003), the Project of National Natural Science Foundation of China (70772029), the Foundation of Science Research Development of Hefei University of Technology (081105F) and the Special Foundation for Doctor Degree to Hefei University of Technology ( 2010HGBZ0617).

\section{References}

1. F. Herrera and E. Herrera-Viedma, Linguistic decision analysis: steps for solving decision problems under linguistic information, Fuzzy Sets and Systems 115 (2000) 67-82.

2. F. Herrera, E. Herrera-Viedma and J.L. Verdegay, Direct approach processes in group decision making using linguistic OWA operators, Fuzzy Sets and Systems 79 (1996) 175-190.

3. X. B. Li, D. Ruan, J. Liu and Y. Xu, A Linguistic-Valued Weighted Aggregation Operator to Multiple Attribute Group Decision Making with Quantative and Qualitative Information, International Journal of Computational Intelligence Systems, 1(3) (2008) 274-284.

4. M. Delgado, F. Herrera, E. Herrera-Viedma, et al. Combining numerical and linguistic information in group decision making, Inf. Sci. 107 (1998) 177-194.

5. Luis Martinez, J Liu, D. Ruan and J. B. Yang, Dealing with heterogeneous information in engineering evaluation processes, Inf. Sci. 177(7) (2007) 1533-1542.
6. Z. S. Xu, Uncertain linguistic aggregation operators based approach to multiple attribute group decision making under uncertain linguistic environment, Inf. Sci. 168 (2004) 171-184.

7. F. Chiclana, F. Herrera and E. Herrera-Viedma, Integrating three representation models in fuzzy multipurpose decision-making based on fuzzy preference relation, Fuzzy Sets and Systems 97 (1998) 1-50.

8. E. Herrera-Viedma, L. Martinez, F. Mata, et al. A Consensus Support System Model for Group Decision Making Problems with Multigranular Linguistic Preference Relations, IEEE Transactions on Fuzzy Systems, 13 (2005) 644-658.

9. F. Herrera and L. Martinez, A 2-tuple fuzzy linguistic representation model for computing with words, IEEE Transactions on Fuzzy Systems 8(6) (2000) 746-752.

10. H. J. Wang, G. W. Wei, X. F. Zhao and R. Lin, Models for Multiple Attribute Group Decision Making with 2Tuple Linguistic Assessment Information, International Journal of Computational Intelligence Systems, 3(3) (2010) 315-324.

11. G. Bordogna, M. Fedrizzi and G. Pasi, A linguistic modelling of in group decision making based on OWA operations, IEEE Transactions on Systems, Man and Cybernetics 27 (1997) 126-132.

12. Xiaobing Li, Da Ruan, Jun Liu and Yang Xu, A Linguistic-Valued Weighted Aggregation Operator to Multiple Attribute Group Decision Making with Quantative and Qualitative Information, International Journal of Computational Intelligence Systems, 1(3) (2008) 274-284.

13. C. L. Hwang and K. Yoon (eds.), Multiple Attributes Decision Making: Methods and Applications, (Springer, Berlin Heidelberg, 1981).

14. S. Cheng, C. W. Chan and G. H. Huang, An integrated multi-criteria decision analysis and inexact mixed integer linear programming approach for solid waste management, Engineering Applications of Artificial Intelligence 16 (2003) 543-554.

15. Y. J. Lai, T. Y. Liu and C. L Hwang, TOPSIS for MODM, European Journal of Operational Research 76 (1994) 486-500.

16. H. C .Liao, Using PCR-TOPSIS to optimize Taguchi's multi-response problem, The International Journal of Advanced Manufacturing Technology 22 (2003) 649-655.

17. D. L. Olson, Comparison of weights in TOPSIS models, Mathematical and Computer Modeling 40 (2004) 721727.

18. S. H. Zanakis, A. Solomon, N. Wishart and S. Dublish, Multi-attribute decision making: A simulation comparison of select approaches, European Journal of Operational Research 107 (1998) 507-529.

19. T. Kaya, Multi-attribute Evaluation of Website Quality in E-business Using an Integrated Fuzzy AHPTOPSIS 
Methodology, International Journal of Computational Intelligence Systems, 3(3) (2010) 301-314.

20. C. Kahraman, A. C. Tolga, An Alternative Ranking Approach and Its Usage in Multi-Criteria Decision-Making, International Journal of Computational Intelligence Systems, 2(3) (2009) 219-235.

21. T. C. Chu and Y. C. Lin, A fuzzy TOPSIS approach for robot selection, The International Journal of Advanced Manufacturing Technology 21 (2003) 284-290.

22. G. R. Jahanshahloo, F. Hosseinzadeh Lotfi and M. Izadikhah, An algorithmic approach to extend TOPSIS for decision making problems with interval data, Applied Mathematics and Computation 175 (2006) 1375-1384.

23. Yu-Jie Wang and Hsuan-Shih Lee, Generalizing TOPSIS for fuzzy multiple-criteria group decision-making, Computers and Mathematics with Applications 53 (2007) 1762-1772.

24. Hsu-Shih Shih, Incremental analysis for MCDM with an application to group TOPSIS, European Journal of Operational Research 186 (2008) 720-734.

25. Hsu-Shih Shih, Huan-Jyh Shyur and E. Stanley Lee, An extension of TOPSIS for group decision making, Mathematical and Computer Modelling 45 (2007) 801-813.
26. C. T. Chen, Extensions of the TOPSIS for group decision-making under fuzzy environment, Fuzzy Sets and Systems 114 (2000) 1-9.

27. Hsu-Shih Shih, Chih-Hung Wang and E.S. Lee, A multiattribute GDSS for aiding problem solving, Mathematical and Computer Modelling 39 (11-12) (2004) 1397-1412.

28. Y. Nakahara, M. Sasaki and M. Gen, On the linear programming problems with interval coefficients, International Journal of Computer Industrial Engineering 23 (1992) 301-304.

29. Z. S. Xu and C. P. Wei, A consistency improving method in the analytic hierarchy process, European Journal of Operational Research 116 (1999) 443-449.

30. X. B. Liu, M. Zhou, J. B. Yang and S. L. Yang, Assessment of strategic R\&D projects for car manufacturers based on the evidential reasoning approach, International Journal of Computational Intelligence Systems, 1(1) (2008) 24-49. 